\title{
Clinical Approach for Diagnosis and Treatment of Burning Mouth Syndrome
}

\author{
Sulafa M Elhassan and Yousif I Eltohami* \\ Department of Oral and Maxillofacial Surgery, University of khartoum, Sudan
}

Submission: June 14, 2020; Published: July 06, 2020

*Corresponding author: Yousif Idris Eltohami, Assistant Professor, Department of Oral and Maxillofacial Surgery, Faculty of Dentistry, University of Khartoum, Sudan

\section{Abstract}

Burning mouth syndrome [BMS] is a chronic pain condition, characterized by an intraoral burning sensation in the absence of any organic disorders of the oral cavity or clinical or laboratory findings, affecting predominantly postmenopausal middle-aged females. This condition is probably of multifactorial origin, involving various local, systemic, and/or psychogenic causes, often idiopathic and its exact etiopathogenesis remains unclear. As the symptom of oral burning is seen in various pathological conditions, it is essential for a clinician to be aware of how to differentiate between symptom of oral burning and BMS as it is a disease of exclusion.

With its management still remaining to be a challenge, In this article we discuss current management strategies from the use of pharmacological modalities to applying non-pharmacological modalities including cognitive behavioral therapy and complementary and alternative medicine [CAM], emphasizing the important role of patient education and anxiety management to improve the patients' quality of life.

Keywords: BMS; Idiopathic; Differentiate; Diagnosis; Management; Pharmacological; Nonpharmacological

\section{Introduction}

Burning mouth syndrome was referred to by Various synonyms in the past such as scalded mouth syndrome, burning lips syndrome, stomatopyrosis, glossopyrosis, sore mouth, sore tongue, oral dysesthesia, stomatodynia, and glossodynia [when confined to the tongue]. International headache society defined BMS as an intraoral burning or dysaesthetic sensation, recurring daily for more than 2 hours daily over more than 3 months, without clinically evident causative lesions [1]. The International Association for the Study of Pain defines BMS as "burning pain of the tongue and/or other oral mucous membrane in the absence of clinical signs or laboratory features [2], which occurs predominantly in peri- and postmenopausal females [3].

In addition to burning sensation, patients with BMS can complain from gustatory disturbances such as dysgeusia [distortion in the sense of taste], parageusia, and subjective xerostomia [dry mouth]. It most often involves the tongue with or without extension to the lips and oral mucosa. The aim of this review is to familiarize healthcare providers with the general characteristics of BMS, clinical approach for diagnosis of BMS while updatiog them with the current treatment options to better manage this group of patients. Epidemiology

The prevalence of BMS in the adult population has been reported to be between 0.7 and 3.7\% [4], where it has never been reported in adolescence and children [5]. The syndrome basically is a disorder of middle-aged and elderly individuals with an age range of 38-78 years [6] with female predominance of 7:1 [7], to $16: 1$ in various literature studies [8], and particularly among peri- and post-menopausal women where the prevalence ranges between $12 \%$ to $18 \%$ [9].

\section{Classification}

Various attempts were made to classify BMS, first one By Lamey and Lewis depending on the intensity of pain into three types:

a) Type 1 [35\%] is characterized by patients having burning sensation every day. The burning is absent on waking but presents as the day goes on, being maximal in the evening. This type may be linked to systemic disorders, such as nutritional deficiencies and endocrine disorders.

b) Type $2[55 \%]$ is characterized by burning sensation that occurs every day, which is present on awakening and often makes falling asleep at night difficult. This subgroup of patients often reports mood changes, alterations in eating habits, and decreased desire to socialize, which seem to be attributable to an altered sleeping pattern. 
Global Journal of Otolaryngology

Table 1: Reported etiological factors for BMS.

\begin{tabular}{|c|c|c|}
\hline Local & Systemic & Psychological \\
\hline Dental & Deficiencies & Depression \\
\hline illfitting dentures & Iron (anemia) & Anxiety \\
\hline Denture materials & B1, B2, B6 & stress \\
\hline Dental anomalies & B12 & Obsessive compulsive disorder \\
\hline Dental treatment & Folate & Somatoform disorder \\
\hline Dental restorations & Zinc & Psychosocial stressors \\
\hline Orthodontic appliances & Vitamins & Cancerphobia \\
\hline Galvanism & Endocrine & \\
\hline Mechanical factors & Diabetes & \\
\hline Parafunctional habits & Thyroid disease & \\
\hline Clenching & Menopause & \\
\hline Bruxism & Hormonal deficiencies & \\
\hline Tongue posture & GIT anomalies & \\
\hline Cheek/lip biting & crohns disease & \\
\hline Myofascial pain & ulcerative colitis & \\
\hline Allergic reactions & Esophageal reflux & \\
\hline lichenoid reactions & Salivary gland alterations & \\
\hline stomatitis & Sjogren's syndrome & \\
\hline medicamentosa & Hyposalivation & \\
\hline Caustic oral rinses & Sicca syndrome & \\
\hline Acidic foods & Radiation therapy & \\
\hline Preservatives & Salivary gland disorders & \\
\hline Additives & Druginduced & \\
\hline Flavorings & Connective tissue disease & \\
\hline Dental materials & Peripheral neuropathies & \\
\hline Neurological factors & Renal stomatitis & \\
\hline Referred from tonsils & Medication & \\
\hline or teeth & Antihyperglycemic & \\
\hline Trigeminal neuropathy & ACE inhibitors & \\
\hline Acoustic neuroma & Antidepressants (tricyclic) & \\
\hline Glossopharyngeal neuralgia & L-thyroxines & \\
\hline Infections & Antihistamines & \\
\hline Bacterial & Antiretrovirals & \\
\hline \multirow{2}{*}{\multicolumn{3}{|c|}{$\begin{array}{c}\text { Fungal } \\
\text { Viral }\end{array}$}} \\
\hline & & \\
\hline \multicolumn{3}{|l|}{ Diseases of oral mucosa } \\
\hline \multicolumn{3}{|l|}{ apthous stomatitis } \\
\hline \multicolumn{3}{|l|}{ migratory glossitis } \\
\hline \multicolumn{3}{|l|}{ Fissured tongue } \\
\hline \multicolumn{3}{|l|}{ OSMF } \\
\hline \multicolumn{3}{|l|}{ Periodontitis } \\
\hline \multicolumn{3}{|l|}{ Autoimmune diseases lichen planus } \\
\hline DLE & & \\
\hline oral pemphigus & & \\
\hline
\end{tabular}

BMS: Burning mouth syndrome, ACE: Angiotensin converting enzyme. 


\section{Global Journal of Otolaryngology}

c) Type $3[10 \%]$ is characterized by intermittent burning, present only on some days, with burning affecting unusual sites such as the floor of the mouth, buccal mucosa, and throat. These patients frequently display anxiety and allergic reactions, particularly to food additives [10].

\section{Scala et al. [6] classified BMS into}

a) Primary [essential/idiopathic] BMS: For which no organic local/systemic causes are identified

b) Secondary BMS: Resulting from local/systemic pathological conditions, and thus this form responds well to the etiology-directed therapy [6].

Based on the level of pathology involved, Jaaskelainen categorized primary BMS into three subgroups with some overlapping in individual patients: The first subgroup is characterized by peripheral small diameter fiber neuropathy of oral mucosa. The second subgroup consist of pathology involving the lingual, mandibular, or trigeminal system. The third subgroup labeled as having central pain, that may involve the hypofunction of dopaminergic neurons in the basel ganglia [11].

\section{Etiopathogenesis}

The exact cause of primary BMS remains unclear, and its widely presumed to be multifactorial involving the interaction between neurophysiological mechanisms and psychological factors [12]. Multiple theories have been put behind the etiopathogenesis of primary BMS including an abnormal interaction between the sensory functions of facial and trigeminal nerves [13]. According to this theory, certain individuals labeled as supertasters [mainly females] due to the high density of fungiform papilla present on the anterior aspect of tongue, are at risk of developing burning pain [14], Bartoshuk confirmed her suspicion that burning mouth syndrome in postmenopausal women was caused by an abnormal activation of the oral pain center in the brain linked to supertasters [15].

Another theory is that Sensory dysfunction associated with small and/or large fiber neuropathy is behind the etiopathogenesis of BMS [16]. Forssell et al. found that almost $90 \%$ of individuals with BMS had some form of altered sensory threshold and/or blink reflex reaction. Lauria et al. [17] Immunohistochemical and microscopic observations revealed axonal degeneration of epithelial and subpapillary nerve fibers in the affected epithelium of the oral mucosa hypothesizing that trigeminal small-fiber sensory neuropathy is involved in BMS etiology. Woda et al. [18] proposed that neurodegeneration associated with the drastic decline of neuro-steroids following the concomitant falls of gonadal and adrenal steroids in skin and oral mucosa as a result of chronic stress and anxiety as a possible mechanism for BMS [18].

The relationship with menopause is proven by the suggestion that the dramatic fall in gonadal steroids that occurs at that time further alters the production of neuroactive steroids [19]. Tatullo $\mathrm{M}$ et al. [20] conducted a study to assess the correlation between the BMS and oxidative stress, in which Oxidative stress assessment was performed by means of an integrated analytical system. Study results indicated that female patients affected by BMS show significantly different oxidant capacity and biological antioxidant potential as iron-reducing activity levels, like those present in oxidative stress condition with respect to the general population. Thus, confirming the effectiveness of antioxidant treatments in these patients to prevent or decrease the onset of oxidative stress [20]

Zidverc Trajkovic et al. [21] found that levels of calcitonin gene related peptide, which is implicated in the development of pain and hyperalgesia were not elevated in saliva of BMS patients and proposed that trigeminal nerve degeneration may be the underlying cause of BMS [21]. Grushka and Bartoshuk suggested that taste alterations could be explained by damage to any special sensory nerve responsible for carrying taste, that is, glossopharyngeal, vagus, chorda tympani, and greater petrosal nerve. According to them, damage to any nerve that supplies taste affects the central inhibitory mechanism normally present between them.

The authors propose that as this inhibition also occurs between the chorda tympani and lingual nerves, damage to the first consequently results in exacerbation of general sensation, such as pain, carried by the latter. Heckmann et al, also suggested that disturbances in the autonomic innervation and oral blood flow are responsible for BMS [22].

\section{Diagnosis}

BMS is a disease of exclusion as it's diagnosed in the absence of any oral clinical changes or any underlying factor that can cause similar oral burning sensation as BMS is defind by IHS as "an intraoral burning sensation for which NO dental or medical cause is found" [23]. several factors can cause the symptom of oral burning or in other terms secondary BMS, and they can be further subdivided into local, systemic and psychological factor.

It is essential that the healthcare provider can differentiate primary BMS from secondary BMS. When the cause can be identified as in the case of secondary BMS, it should be treated, and the symptoms should successfully disappear. The diagnosis of BMS is based on the exclusion of all possible local and systemic factors that are known to cause burning mouth sensation as shown in Algorithm 1. The diagnostic criteria developed by Scala et al., for the diagnosis of BMS are as follows [6]

\section{Fundamental criteria}

a) Daily deep burning sensation of the bilateral oral mucosa.

b) Burning sensation for at least 4-6 months.

c) Constant intensity or increasing intensity during the day.

d) No worsening on eating or drinking. Instead, the burning sensation may reduce.

e) No interference with sleep. 


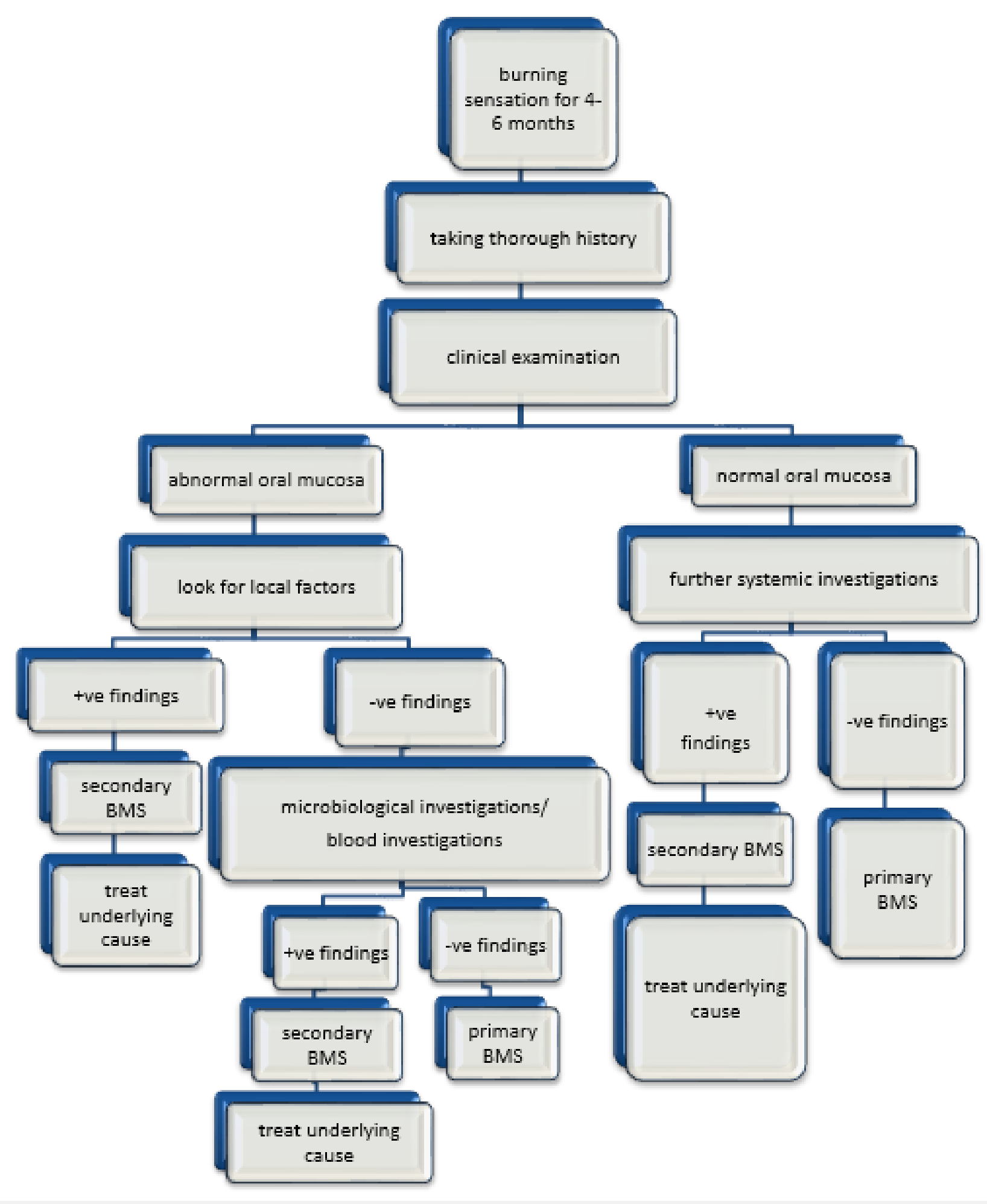

Algorithm 1: Clinical steps for diagnosis of BMS.

\section{Additional criteria}

a) Dysgeusia and/or xerostomia. b) Sensory or chemosensory alterations.

c) Mood changes or psychopathological alterations. 
A through and comprehensive history along with clinical examination and laboratory tests is the key to diagnosis of BMS [30].

History should include:

a) Duration, intensity, location, aggravating, and relieving factors of pain.

b) Taste alteration and dry mouth.

c) Current and past health status like hypertension, diabetes etc.

d) Medications [current and past].

Clinical examination should include:

a) Examination of dental hard and soft tissues.

b) Inspection of oral mucosa and tongue for any lesion swelling, change in color, etc.

c) Tempro-mandibular joint examination.

d) Palpation of muscles of mastication.

e) Assessment of denture fit and function [when found].

Tests should include:

a) Hematological test: Complete blood count, glucose test, thyroid test etc.

b) Oro - microbial culture for fungal, viral, and bacterial infections.

c) Allergy testing.

d) Salivary flow rate tests.

e) MRI, CT scans, and nuclear medicine test to rule out systemic diseases/disorders.

f) Gastric reflux studies.

\section{Clinical Presentation}

Patients usually complains of the classic triad of chronic oral mucosal burning pain associated with dysgeusia and xerostomia with no visible disease in the oral mucosa for 4-6 months duration [5]. Clinical presentations may vary as some patients can be oligosymptomatic [pain and dysgeusia or xerostomia] or monosymptomatic [pain only] [6]. In general, $63 \%$ of patients report accompanying dry mouth, $60 \%$ of patients may report bitter/metallic taste, and 35\% may complain of altered taste perception [20]. The pain in BMS cases is usually described as a chronic, burning or scalding type, sometimes with itching sensation or numbness of the tongue, and other oral mucosal surfaces [25]. The onset of pain can be either gradual and spontaneous or sudden and related to a precipitating event such as any dental procedure.
Typically, pain is localized to the tongue and sometimes involving other mucosal surfaces also such as palate, lip, buccal mucosa, and floor of the mouth. The pain might be continuous or intermittent, mild to moderate in intensity, localized to the oral cavity and does not radiate to other regions of the face. It typically relieves on intake of food or liquids, which contrasts with burning symptom in other diseases; in which the pain aggravates $[21,24,26,27]$. It is found to be associated with consumption of hot/spicy food, too much speaking, stressful life and subsides with cold food, work, and distraction [28]. These patients often present mood changes, including irritability, anxiety, and depression. Grushka M et al. [5] reported that some patients complain of sleep onset and may wake up during the sleep because of pain [29]. Xerostomia is a concomitant symptom in patients with BMS, prevalence varying between 34 and 39\%, while Grushka et al. [29] found that this is equal to or greater than $60 \%$. In contrast, some authors consider that the composition [increased concentrations of $\mathrm{K}+, \mathrm{Na}+, \mathrm{Cl}-, \mathrm{Ca}+2$, immunoglobulin $\mathrm{A}$, amylase] of the saliva could play a major role in the pathogenesis of BMS [30].

\section{Management}

BMS can significantly impact quality of life, [31], 70\% of BMS patients report mood changes and over half have changed their eating habits following the onset of BMS. More significantly, 20\% of BMS patients experience depression and a reduced desire to socialize [8]. So, a key aim of BMS management is to provide psychological support by recognizing and acknowledging the patient's symptoms, in addition to exploring and addressing issues which may contribute to their symptoms. This is combined with pharmacological and non-pharmacological management for symptom control [32]. It is important to know that in most of the patients the disease is self-limiting, not exceeding three years, regardless of the treatment modality used [29]. The first step in managing BMS is to differentiate primary BMS from the secondary type, cause targeting of the underlying factor in secondary BMS can be quite enough to get rid of the symptom of oral burning sensation. However, in the case of primary or idiopathic BMS, the management is still considered somewhat challenging and remains obscure [23].

Different treatment modalities as shown in table 3 were suggested for the management of BMS starting with informing the patient about the disease nature and calming and reassuring him. Some authors advocated the use pharmacological methods topical or systemic, topical agents as clonazepam at dose of 0.25 to $2 \mathrm{mg}$ rinse, Local anesthetic [lignocaine or benzocaine viscous gel], desensitizing agents [capsaicin cream $0.25 \mathrm{mg}$ ], topical Antidepressant [doxepin cream], or Mucosal protectant [sucralfate oral rinse, artificial saliva]. And systemic drugs like benzodiazepines [ chlordiazepoxide at dose of 10-30mg a day], Anticonvulsants [gabapentin 300-1500mg per day], tricyclic antidepressants [[10-150mg per day], Antioxidants as alpha lipoic acid. 
while others hit toward the other direction of using psychological non pharmacological methods such as Cognitive behavioral therapy, Group psychotherapy, Electroconvulsive therapy, Yoga, Meditation and Relaxation therapies, acupuncture and laser therapy Grushka, 2005 has suggested that the combination of medications such as benzodiazepines, gabapentin, and TCA could be more efficient in treating BMS. According to the author, low doses of several medications might be more effective, as this reduces the undesirable side effects provoked at higher doses [33]. However, a recent study conducted by Motoko W et al, showed a real worldwide discontinuation of antidepressants as discontinuation due to lack of efficacy was observed in 88 patients [73.9\%] for amitriptyline and 21 patients [67.7\%] for aripiprazole. The proportion of patients continuing the same medication until the end of observation was $21.2 \%$ [32/151] for amitriptyline and $34.0 \%$ [16/47] for aripiprazole, with no significance, [34] plus the fact that the population of elderly patients with BMS has recently increased, in parallel with an increasingly aging society [35]. It is necessary to be particularly cautious when prescribing amitriptyline to elderly patients.

Regarding the use of topical clonazepam , In a study with 25 patients Woda et al., dissolved clonazepam $1.0 \mathrm{mg}, 3$ times/day for $3 \mathrm{~min}$ in the mouth with $66 \%$ of patients reporting a reduction in symptoms, and $29 \%$ reporting partial reduction in symptoms after 6 months. Gremeau-Richard et al. [36], in a randomized placebo-controlled study instructed the patients to suck a tablet of $1 \mathrm{mg}$ of clonazepam [or placebo] and hold their saliva near the pain location without swallowing for $3 \mathrm{~min}$ and then to spit, repeating this protocol 3 times a day for 14 days, the authors concluded that topical administration of clonazepam improves intraoral burning sensation in some but not in all BMS patients [37]. Rodríguez de Rivera Campillo et al. also reported benefits of using clonazepan topically [38].

Conducted a double-blind study using clonazepam [0.5mg/ day] and found that patients significantly improved in pain rating as compared to placebo [lactose] [39]. Local application of desensitizing agents such as topical capsaicin a desensitizer of neural receptors for inflammation, and the use of hot pepper sauce [a good source of capsaicin] in water in the ratio of 1:2 is also found to be effective in reducing oral pain in BMS [40]. Silvestre et al. [41] in a prospective, double-blind crossover study concluded that capsaicin rinse [0.02\%] for one week was effective however it is use present some limitations [41]. In a pilot study, Petruzzi et al. [42] used systemic capsaicin $0.25 \% 3 \mathrm{x}$ day and had a significant reduction in pain levels though $32 \%$ reported major gastric pain [42].

Recently, Toida et al. [43] reported in a randomized controlled trial a significant improvement in pain levels of BMS patients using lafutidine, $10 \mathrm{mg}$ twice daily for 12 weeks, lafutidine is a histamine $\mathrm{H} 2$ receptor antagonist that has a sensitive effect on capsaicin-sensitive afferent neurons. According to the authors, oral administration of lafutidine is safe and effective in reducing oral burning symptoms. Volpe et al. [44] in his study on postmenopausal women, found that 12 out of 22 patients experienced improvement in oral symptoms after estradiol-based treatment. Femiano et al. [45], have shown the use of alpha lipoic acid in management of BMS, $96 \%$ of patients had shown significant improvement in their symptoms as it is a potent antioxidant and neuroprotective agent [46].

A double-blind placebo-controlled trial was conducted in order to evaluate the efficacy of alpha lipoic acid [ALA] and determine the statistical significance of the outcome variables, $64 \%$ of ALA patients reported some level of improvement, with a level of maintenance of $68.75 \%$ one month after treatment. $27.6 \%$ of the placebo group also demonstrated some reduction in BMS symptoms. However, Cavalcanti et al. [47] in their randomized, double-blind, placebo-controlled trial of 38 patients, did not find effectiveness of alpha lipoic acid, in comparison with the control group given placebo, in the management of BMS [48]. Recent randomized double blind placebo controlled trial by Lopez D et al. $[42,49]$ showed that use of gabapentin alone [300 mg daily] or in combination with ALA [600 mg daily] was beneficial in reducing symptoms in $50 \%$ and $70 \%$ of patients with BMS, respectively, compared to placebo [15\%] [50,51].

On the other direction Individual or small-group cognitivebehavioural therapy has been shown to reduce the intensity of the pain of the BMS in a significant number of sufferers, either alone or with medications $[23,52]$. Cognitive-behavioural therapy is a directed, structured, short-term psychological treatment aimed at correcting dysfunctional emotional responses such as pain, fear, helplessness, vulnerability, or exhaustion, by changing thoughts and behaviours [53]. In a study by Bergdahl J et al. [54] Weekly one-hour sessions of cognitive behavioral therapy lasting for 1215 weeks significantly reduced oral burning symptom in all study patients compared to placebo control group, with an estimated $27 \%$ of patients remaining symptom-free at 6 month follow-up [54]. Mock \& Chugh [55] and Reamy et al. [24] found that the better method would be the combination of cognitive behavioral therapy, alpha lipoic acid, and/or clonazepam.

\section{Conclusion}

In conclusion, BMS is a serious condition affecting mostly post-menopausal women and elderly, leading them to a life filled with stress and anxiety and affecting their quality of life, especially that it's still quite debatable regarding both its etiology and management, a lot of cases across the world can attend dental clinics without being recognized or dealt with in the Wright manner which leads the patient into feeling more frustrated and depressed, Clinicians should pay more attention, starting with reassuring the patient, working their way into making an accurate diagnosis, ending with choosing the most suitable method of treatment for the patient's condition with regular follow-ups. 


\section{Global Journal of Otolaryngology}

\section{References}

1. International Headache Society (2019) The International Classification of Headache Disorders.

2. Burning Mouth Syndrome in Fact Sheets (2016) International Association for Study of Pain.

3. Malik R, Goel S, Misra D, Panjwani S, Misra A (2012) Assessment of anxiety and depression in patients with burning mouth syndrome: A clinical trial. J Midlife Health 3: 36-39.

4. Bergdahl M, Bergdahl J (1999) Burning mouth syndrome: prevalence and associated factors. J Oral Pathol Med 28(8): 350-354.

5. Lopez Jornet P, Camacho Alonso F, Andujar Mateos P, Sanchez Siles M, Gomez Garcia F (2010) Burning mouth syndrome: An update. Med Oral Patol Oral Cir Bucal 15: e562-568.

6. Scala A, Checchi L, Montevecchi M, Marini I, Giamberardino MA (2003) Update on burning mouth syndrome: Overview and patient management. Crit Rev Oral Biol Med 14: 275-291.

7. Savage NW (1996) Burning mouth syndrome: patient management. Aust Dent J 41(6): 363-366.

8. Grushka M (1987) Clinical features of burning mouth syndrome. Oral surg Oral Med Oral Pathol 63: 30-36.

9. Sun A, Wu KM, Wang YP, Lin HP, Chen HM, Chiang CP (2013) Burning mouth syndrome: A review and update. J Oral Pathol Med 42: 649-655.

10. Lamey PJ, Lewis MA (1989) Oral medicine in practice: Burning mouth syndrome. Br Dent J 167: 197-200.

11. Jaaskelainen SK (2012) Pathophysiology of burning mouth syndrome. Clin Neurophysiol 123: 71-77.

12. Aravindhan R, Vidyalakshmi S, Kumar MS, Satheesh C, Balasubramanium AM, et al. (2014) Burning mouth syndrome: A review on its diagnostic and therapeutic approach. J Pharm Bio allied Sci 6(1): S21-25.

13. Grushka M, Epstein JB, Gorsky M (2003) Burning mouth syndrome and other oral sensory disorders: A unifying hypothesis. Pain Res Manag 8: 133-135.

14. Bartoshuk LM, Snyder DJ, Grushka M, Berger AM, Duffy VB, et al (2005) Taste damage: Previously unsuspected consequences. Chem Senses 30(1): i218-219.

15. Bartoshuk (2017) Accounting for Taste. yale school of medicine 31.

16. Forssell H, Jääskeläinen S, Tenovuo O, Hinkka S (2002) Sensory dysfunction in burning mouth syndrome. Pain 99: 41-47.

17. Lauria G, Majorana A, Borgna M, Lombardi R, Penza P, et al. (2005) Tri geminal small-fiber sensory neuropathy causes burning mouth syndrome. Pain 115: 332-327.

18. Woda A, Dao T, Gremeau Richard C (2009) Steroid dysregulation and stomatodynia (burning mouth syndrome). J Orofac Pain 23: 202-210.

19. Jääskeläinen SK, Rinne JO, Forssell H, Tenovuo O, Kaasinen V, et al (2001) Role of the dopaminergic system in chronic pain-A fluorodopa-PET study. Pain 90: 257-260.

20. Tatullo M, Marrelli M, Scacco S, Lorusso M, Doria S, et al. (2012) Relationship between oxidative stress and "burning mouth syndrome" in female patients: A scientifi c hypothesis. Eur Rev Med Pharmacol Sci 16: 1218-1221.

21. Zidverc Trajkovic J, Stanimirovic D, Obrenovic R, Tajti J, Vécsei L, et al (2009) Calcitonin gene-related peptide levels in saliva of patients with burning mouth syndrome. J Oral Pathol Med 38: 29-33.
22. Heckmann SM, Heckmann JG, HiIz MJ, Popp M, Marthol H, et al. (2001) Oral mucosal blood flow in patients with burning mouth syndrome. Pain 90: 281-286.

23. Gurvits GE, Tan A (2013) Burning mouth syndrome. World J Gastroenterol 19: 665-672.

24. Reamy BV, Derby R, Bunt CW (2010) Common tongue conditions in primary care. Am Fam Physician 81: 627-634.

25. Brailo V, Vuéiaeeviae Boras V, Alajbeg IZ, Alajbeg I, Lukenda J, et al (2006) Oral burning symptoms and burning mouth syndrome-significance of different variables in 150 patients. Med Oral Patol Oral Cir Bucal 11: E252-255.

26. Ashish A, Sunil RP (2012) Burning mouth syndrome: A diagnostic and therapeutic dilemma J Clin Exp Dent 4: e180-185.

27. Salort Llorca C, Mínguez Serra MP, Silvestre FJ (2008) Drug-induced burning mouth syndrome: A new etiological diagnosis. Med Oral Patol Oral Cir Bucal 13: E167-170.

28. Dahiya P, Kamal R, Kumar M, Niti, Gupta R, et al. (2013) Burning mouth syndrome and menopause. Int J Prev Med 4: 15-20.

29. Grushka M, Epstein JB, Gorsky M (2002) Burning mouth syndrome. Am Fam Physician 65: 615-620.

30. Paula AN, Andressa VB, Francisco GP, Elaine MS (2009) Burning mouth syndrome: A discussion about possible etiological factors and treatment modalities. Braz J Oral Sci 8: 62-66.

31. Lopez Jornet P, Camacho Alonso F, Lucero Berdugo M (2008) Quality of life in patients with burning mouth syndrome. J Oral Pathol Med 37: 389-394.

32. Danny Cheung, Nigel Trudgill (2015) Managing a patient with burning mouth syndrome. Frontline Gastroenterol 6(3): 218-222.

33. Grushka M (2005) Burning Mouth Syndrome, Proceedings of American of Oral Medicine and American of Orofacial Pain Meeting, Phoenix AZ, EUA.

34. Motoko Watanabe, Miho Takenoshita, Trang TH Tu, Akira Toyofuku (2019) Real-world Discontinuation of Antidepressant Treatment in Patients with Burning Mouth Syndrome: A Chart Review, Pain Medicine 1-2.

35. Tu TTH, Takenoshita M, Matsuoka H, Watanabe T, Suga T, et al. (2019) Current management strategies for the pain of elderly patients with burning mouth syndrome: A critical review. Biopsychosoc Med 13: 1.

36. Woda A, Navez ML, Picard P, Gremeau C, Pichard Leandri E (1998) A possible therapeutic solution for stomatodynia (burning mouth syndrome). J Orofac Pain 12: 272-278.

37. Gremeau Richard C, Woda A, Navez ML, Attal N, Bouhassira D, et al. (2004) Topical clonazepam in stomatodynia: A randomized placebo-controlled study. Pain 108: 51-57.

38. Rodríguez de Rivera Campillo E, López López J, Chimenos Küstner E (2010) Response to topical clonazepam in patients with burning mouth syndrome: A clinical study. Bull Group Int Rech Sci Stomatol Odontol 49: 19-29.

39. Heckmann SM, Kirchner E, Grushka M, Wichmann MG, Hummel T (2012) A double-blind study on clonazepam in patients with burning mouth syndrome. Laryngoscope 122: 813-816.

40. Epstein JB, Marcoe JH (1994) Topical application of capsaicin for treatment of oral neuropathic pain and trigeminal neuralgia. Oral Surg Oral Med Oral Pathol 77: 135-140. 
41. Silvestre FJ, Silvestre Rangil J, Tamarit Santafé C, Bautista D (2012) Application of a capsaicin rinse in the treatment of burning mouth syndrome. Med Oral Patol Oral Cir Bucal 17: e1-4.

42. Petruzzi M, Lauritano D, De Benedittis M, Baldoni M, Serpico R (2004) Systemic capsaicin for burning mouth syndrome: Short-term results of a pilot study. J Oral Pathol Med 33: 111-114.

43. Toida M, Kato K, Makita H, Long NK, Takeda T, et al. (2009) Palliative effect of lafutidine on oral burning sensation. J Oral Pathol Med 38: 262-268.

44. Volpe A, Lucenti V, Forabosco A, Boselli F, Latessa AM, et al. (1991) Oral discomfort and hormone replacement therapy in the post-menopause. Maturitas 13: 1-5.

45. Femiano F, Scully C (2002) Burning mouth syndrome (BMS): Double blind controlled study of alpha-lipoic acid (thioctic acid) therapy. J Oral Pathol Med 31: 267-269.

46. Sánchez BP, López LAM, Lapiedra RC, Martínez SL, Gómez GE (2015) Alpha lipoic acid efficacy in burning mouth syndrome. A controlled clinical trial. Med Oral Patol Oral Cir Bucal 20(4): e435-e440

47. Cavalcanti DR, da Silveira FR (2009) Alpha lipoic acid in burning mouth syndrome - A randomized double-blind placebo-controlled trial. J Oral Pathol Med 38: 254-261.

48. López D’alessandro E, Escovich L (2011) Combination of alpha lipoic acid and gabapentin, its effi cacy in the treatment of Burning Mouth Syndrome: A randomized, double-blind, placebo-controlled trial. Med Oral Patol Oral Cir Bucal 16: e635-640.
49. Ambaldhage VK, Puttabuddi JH, Nunsavath PN (2015) Burning mouth syndrome: An update Indian Journal of Pain 29(1): 2-8.

50. Da Silva LA, de Siqueira JT, Teixeira MJ, de Siqueira SR (2014) The role of xerostomia in burning mouth syndrome: A case-control study. Arq Neuropsiquiatr 72: 91-98.

51. Sardella A, Lodi G, Demarosi F, Uglietti D, Carrassi A (2006) Causative or precipitating aspects of burning mouth syndrome: A casecontrol study. J Oral Pathol Med 35: 466-471.

52. O Komiyama, H Nishimura, Y Makiyama, Iida T, Obara R, et al. (2013) Group cognitive-behavioral intervention for patients with burning mouth syndrome. Journal of oral science 55(1): 17-22.

53. AN Kaczkurkin, EB Foa (2015) Cognitive-behavioral therapy for anxiety disorders: An update on the empirical evidence. Dialogues in Clinical Neuroscience 17(3): 337-346.

54. Bergdahl J, Anneroth G, Perris H (1995) Cognitive therapy in the treatment of patients with resistant burning mouth syndrome: A controlled study. J Oral Pathol Med 24: 213-215.

55. Mock D, Chugh D (2010) Burning mouth syndrome. Int J Oral Sci 2: 1-4.

\section{Your next submission with Juniper Publishers will reach you the below assets}

- Quality Editorial service

- Swift Peer Review

- Reprints availability

- E-prints Service

- Manuscript Podcast for convenient understanding

- Global attainment for your research

- Manuscript accessibility in different formats

( Pdf, E-pub, Full Text, Audio)

- Unceasing customer service

Track the below URL for one-step submission https://juniperpublishers.com/online-submission.php 